\title{
Characterization chip formation of commercial steel materials at low speed cylindrical grinding processes
}

\author{
Wahyu Isti Nugroho*, Sri Nugroho, and Rusnaldy \\ Diponegoro University, Department of Mechanical Engineering, 50275, Jl. Prof Soedharto, \\ Tembalang, Semarang, Indonesia
}

\begin{abstract}
Cylindrical grinding is the process of metal removal using multiple cutting point. The objective of the study is to investigate the chip characteristics (shape and width) and surface roughness materials. The materials are AISI 1020, AISI 1045, AISI 1090, AISI D2, and AISI 4340 with a grinding wheels WA46K8V. The research is using cylindrical grinding processes at low-speed workpiece $100 \mathrm{rpm}$, depth of cut $0.5 \mathrm{~mm}$, in dry condition. Result of research is comparing characteristic chip with variable feet rate $120 \mathrm{~mm} / \mathrm{min}, 420 \mathrm{~mm} / \mathrm{min}, 1300 \mathrm{~mm} / \mathrm{min}$. The result is to show the increasing feedrate lead, the growth of chip width and high surface roughness value. On materials AISI 1020, AISI 1045, AISI 1090, and AISI 4340 show that chips width is related to hardness value.
\end{abstract}

\section{Introduction}

Cylindrical grinding is important processes to make part cylindrical with precision and good surface finish. Cylindrical grinding oftens to make the part of cam and shaft from steel materials. Generally, to classify the steels based on hardness and chemical material, it can use hardness tester and chemical material tester. Material properties give influence in machine processes [1]. The mechanical properties of the material include strength, hardness, and ductility correlate to the chip form [2]. By determine the form chip from a cylindrical grinding machine, it can be sure that mechanical properties is formed. The research of chip characteristics attracts many researchers. Because most of them use high spindle speed parameter. It is proven that the characteristic of chip with various grinding wheels and feedrates for different steels can affect the type of chip [3]. Various feedrate and spindle speed for hard steel will give affect to the chip size [4].

Character of chip formation can do to see the quality of the material use. The research shows that the correlation between character of chip formation and mechanical properties materials. To analyze the chip, the variations of feedrates regarding low speed workpiece and the depth of cut should be investigated. Chip from each type of steels with a various feedrates is observed by the perceptions of its formation and dimension.

\footnotetext{
* Corresponding author: w.istinugroho@yahoo.co.id
} 
By extending the publish result from the main frame of the chip formation, this research aim to investigate the feedrate effect on the chip formation of different types of steel materials experimentally. The research shows the correlation between character of chip formation and mechanical properties of materials.

\section{Experimental Method}

The experiment performed by a cylindrical grinding machine is shown in figure 1. Various steels that used for this study are AISI 1020, AISI 1045, AISI 1090, AISI D2, and AISI 4340 which have different hardness value. The dimension of the workpiece is $\varnothing 30 \times 200$ $\mathrm{mm}$. The grinding wheel uses WA46K8V Ø405 x 56 × $127 \mathrm{~mm}$. The following is the details of the experimental setup:
(1) Wheel speed
: $2900 \mathrm{rpm}$
(2) Workpiece spindle speed $\quad: 100 \mathrm{rpm}$
(3) Depth of cut
: $0,5 \mathrm{~mm}$
(4) Feedrate
: a $(120 \mathrm{~mm} / \mathrm{min})$
b $(420 \mathrm{~mm} / \mathrm{min})$
c $(1300 \mathrm{~mm} / \mathrm{min})$
(5) Cooling
: dry process

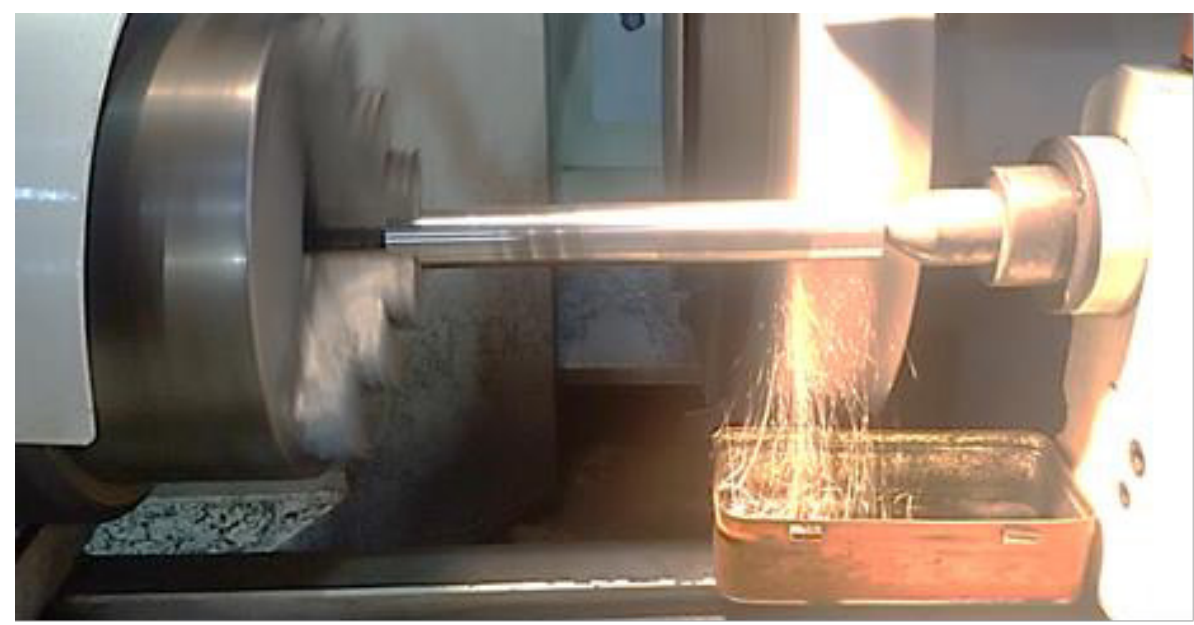

Fig. 1. Set up cylindrical grinding machine.

Cylindrical grinding process low speed without cooling sytem (dry process) has purpose to get an easy chip characterization. As seen in Figure 1 a metal box added in area of chip direction to collect the chip. The chip characterization and measurement using digital microscopes zooms 100x with image processing software. The chip selected based on the criteria good form and dominant.

\section{Result and Discussion}

The chip from the machine process is collected, captured, and measured. Table 1 shows the chip formation of various steels and feedrates. It is can be classified that types of chips are flowing, knife, slice, and spherical shape show in Table 2. This study characteristics of chip's types are flowing chip Figure 3. The formation of chip in the grinding process is affected by the grit on the grinding stone that incisions, the surface of the material. If 
further observed that the mechanism of grinding occurs into three processes namely rubbing, sliding, plowing, and cutting/chipping shown as Figure 2.

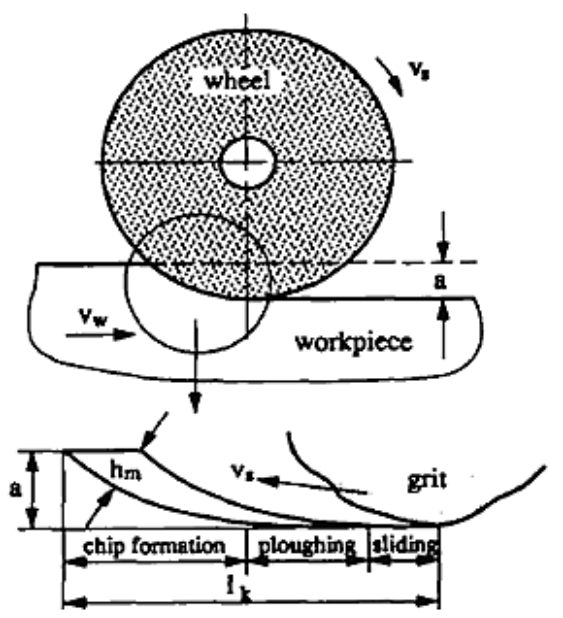

Fig. 2. Mechanism of formation of grinding process grinding [5].

The grinding process is a cutting method using multiple cutting points so that the results from one process of the same parameters produce types forms of chips. The shape and dimensions are influence by the parameters of types of grinding wheel, feedrate, spindle speed, wheel speed, and coolant. Based on the explanation of various types of chip's incisions of the machine process, it can be concluded in Table 2.

Table 1. Chips formation of various steel.

\begin{tabular}{|c|c|c|c|c|c|}
\hline edrate & AISI 1020 & AISI 1045 & AISI 1090 & AISI D2 & AISI 4340 \\
\hline $\begin{array}{c}120 \\
\mathrm{~mm} / \mathrm{min}\end{array}$ & $\int_{0}^{0}$ & $a_{0}^{2}$ & $\underbrace{2}_{-3}$ & & and \\
\hline $\begin{array}{c}420 \\
\mathrm{~mm} / \mathrm{min}\end{array}$ & $\left.\frac{y}{6}\right)^{2}$ & 4 & & $\int_{-}^{3}$ & $\frac{2}{6}$ \\
\hline $\begin{array}{c}1300 \\
\mathrm{~mm} / \mathrm{min}\end{array}$ & 6 - & $r^{64}$ & & & 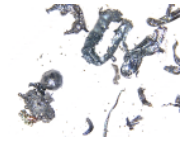 \\
\hline
\end{tabular}

Table 1 shows the higher feedrate resulting large dimension of chip formation. The higher hardness value of steel then produces a smaller chip formation. In AISI D2, it produces the smallest of all steels chip formations because it has high chromium alloy. Chrome alloys cause steel to have abrasive resistance properties and lowest surface roughness value. There is a correlation between characteristics of machining process of the mechanical properties of the materials. 
Table 2. Chip types.

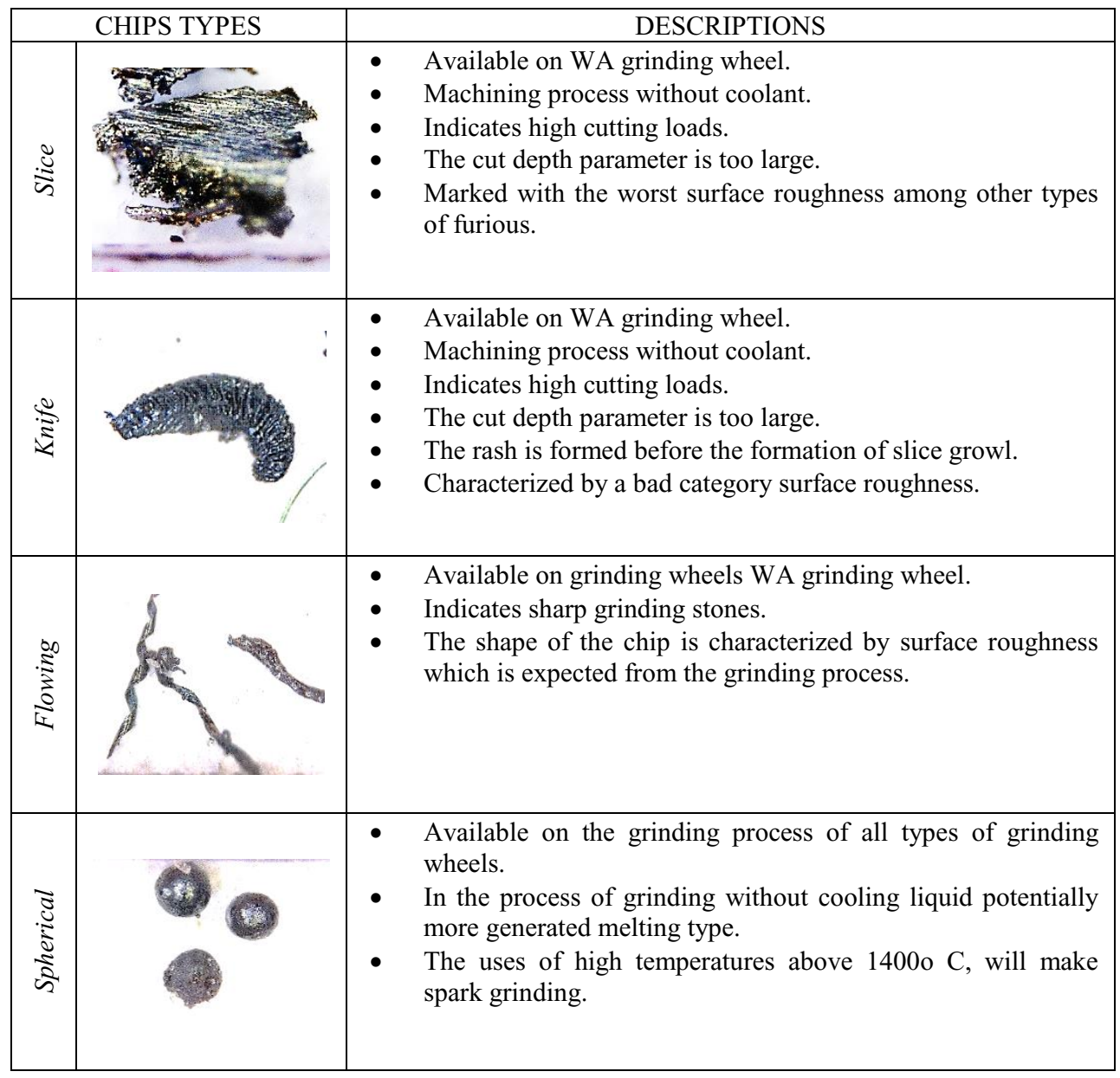

Chip types can indicate machine ability of materials. Slice types available on WA grinding wheel during dry process. That indicates high cutting loads and depth of cut are too large. This chip type are showing worst surface roughness quality. Knife chip types are available on grinding process using WA grinding wheel without cooling system (dry process). It is indicating high cutting loads and high depth of cut. This chip's types formed before the formation of slice types. On flowing types indicates sharp grinding stones and best surface roughness quality. Spherical types available on the of all type grinding wheels. 
Table 3. Relationship of machining characteristics to material properties.

\begin{tabular}{|c|c|c|c|c|}
\hline Materials & $\begin{array}{c}\text { Flowing } \\
\text { chips types }\end{array}$ & $\begin{array}{c}\text { Hardness } \\
\text { Brinell } \\
\end{array}$ & $\begin{array}{l}\text { Chips width } \\
\text { (Flowing) } \mu \mathrm{m}\end{array}$ & $\begin{array}{c}\text { Surface } \\
\text { roughness } \mu \mathrm{m}\end{array}$ \\
\hline $\begin{array}{l}\text { AISI } \\
1020\end{array}$ & & 131 & 108,9 & 5,949 \\
\hline $\begin{array}{l}\text { AISI } \\
1045\end{array}$ & & 195 & 101,6 & 5,736 \\
\hline $\begin{array}{l}\text { AISI } \\
1090\end{array}$ & & 220 & 98 & 5,043 \\
\hline AISI D2 & & 258 & 80,3 & 3,978 \\
\hline $\begin{array}{l}\text { AISI } \\
4340\end{array}$ & & 346 & 91,3 & 4,145 \\
\hline
\end{tabular}

\section{Conclusion}

The effect of feedrates on a chip characteristic varying the steel materials (AISI 1020, AISI 1045, AISI 1090, AISI D2, and AISI 4340) has been examined. Based on the discussion, the following conclusion could be drawn. Increasing the feedrate will increase the chip width of all types materials used. The significant result of this study is to make the chip formation which could be considered as the guide to determine the hardness value of the material AISI 1020, AISI 1045, and AISI 1090.

\section{Reference}

1. William D. Callister, Materials science and engineering an introduction, $8^{\text {th }}$ edition. New Jersey: John Wiley \& Sons, Inc, (2009).

2. B. Denkena, J. Kohler, J. Kastner, Chip formation in grinding : an experimental study, 6, 107-115, (2012).

3. P. Tso, An investigation of chip types in grinding, Material process technology, 53, 521-532, (1995).

4. P. Tso and S. Wu, Analysis of grinding quantities through chip sizes, 95, 2-8, (1999).

5. S. Malkin, Grinding technology theory and applications of machining with abrasives, $2^{\text {nd }}$ Edition. New York, (2008). 